\title{
Nordiques
}

$34 \mid 2017$

La mer Baltique comme zone-frontière : perspectives environnementales, géopolitiques, culturelles

\section{Eiríkur Örn Norðdahl, Heimska. La stupidité}

Métailié, 2017

Philippe Bouquet

\section{QpenEdition \\ Journals}

Édition électronique

URL : https://journals.openedition.org/nordiques/1857

DOI : $10.4000 /$ nordiques. 1857

ISSN : $2777-8479$

Éditeur :

Association Norden, Bibliothèque de Caen la mer

Édition imprimée

Date de publication : 1 novembre 2017

Pagination : 153

ISBN : 9791095914006

ISSN : 1761-7677

\section{Référence électronique}

Philippe Bouquet, «Eiríkur Örn Norðdahl, Heimska. La stupidité », Nordiques [En ligne], 34 | 2017, mis en ligne le 08 novembre 2021, consulté le 27 novembre 2021. URL : http://journals.openedition.org/ nordiques/1857 ; DOI : https://doi.org/10.4000/nordiques.1857

Ce document a été généré automatiquement le 27 novembre 2021.

Nordiques 


\section{Eiríkur Örn Norðdahl, Heimska. La stupidité}

Métailié, 2017

Philippe Bouquet

\section{RÉFÉRENCE}

Eiríkur Örn Norðdahl, Heimska. La stupidité, traduit par Éric Boury, Métailié, 2017

1 Situé dans un avenir sans doute pas très lointain, le livre s'ouvre sur une scène de voyeurisme par webcam interposée brusquement interrompue par une panne de courant. L'acteur masculin en est Áki Talbot, qui cherche à se venger de son excompagne, Lenita (tous deux sont écrivains et en perpétuelle rivalité, à grand renfort d'interviews "people»). C'est d'ailleurs devenu une pratique générale, presque obligatoire, que d'être "connecté », et donc surveillé en permanence et par tout le monde dans ses activités les plus intimes, car il faut être « vu» pour exister. «La vie privée a été sacrifiée à des fins de sécurité et de distraction », est-il dit, et c'est ce qui est appelé dans ce livre « la dystopie de la surVeillance (sic)». Malheureusement le livre se perd ensuite dans une satire assez facile de la vie littéraire islandaise, puis explore longuement les rapports entre Lenita et sa sœur jumelle Tilda. Au bout d'une centaine de pages, il se passe soudain quelque chose: les coupures de courant (et donc d'Internet) se multiplient, la galerie de personnages s'élargit soudain et on bascule brusquement dans une sorte de roman collectif. Les personnages reçoivent un long message d'une certaine Birta Sollilja qui dénonce le présent comme «un suicide de chaque instant» et annonce qu'elle a «éteint la machine». Cet acte de "terrorisme écologique ", dû à quatre étudiants des Beaux-Arts ayant lu les livres d'Áki et de Lenita motive le confinement de la population de la région et entraîne diverses convulsions dues au sevrage informatico-technologique.

2 Ce livre pouvait difficilement être plus différent du précédent de l'auteur : Le mal (même éditeur, 2015). Alors que le premier était long, touffu, complexe, et largement 
historique, celui-ci est bref, mince, brut et tourné vers le futur. Autant le premier était riche jusqu'à risquer de provoquer une migraine chez le lecteur, autant celui-ci est austère et frustrant. Certes, c'est aussi une "sorte de roman" mais d'un genre bien différent, une réflexion presque onirique et bien entendu sans conclusion sur le temps, la vie, l'art, le progrès et une foule d'autres sujets abordés au hasard d'associations d'idées extrêmement idiosyncratiques. On en ressort légèrement surpris de constater que tant d'intelligence et de talent ne mènent à rien de précis, car la dystopie est simplement effleurée, alors qu'il y aurait eu matière à la pousser jusque dans les ultimes recoins d'une étude de la perversion. La stature de l'auteur, déjà bien insaisissable à l'issue de son premier livre, ne fait que gagner en mystère. C'est dû bien plutôt à un excès de dons qu'à un défaut, mais que nous donnera-t-il la prochaine fois, vers quels confins artistiques nous entraînera-t-il ? Il n'est pas sûr qu'il soit capable de le dire lui-même, tant il paraît mû par une énergie créatrice brute et incontrôlée. Une chose est sûre : quoi qu'il fasse, cela ne laissera pas les lecteurs indifférents. 